\title{
SPATIAL VARIATION OF URBAN HEAT ISLAND INTENSITY IN URBAN CITIES USING MODIS SATELLITE DATA
}

\author{
Ruchi Bala, Rajendra Prasad, Vijay Pratap Yadav, Jyoti Sharma \\ Department of Physics, Indian Institute of Technology (BHU), Varanasi \\ ruchibala7@gmail.com, rprasad.app@itbhu.ac.in, victory327759@gmail.com, jyotisharma.rs.phy17@itbhu.ac.in
}

KEY WORDS:- Urban Heat Island, MODIS, Land Surface Temperature, Percent Impervious, Land Cover, Urban

\begin{abstract}
:
Urban Heat Island (UHI) refers to the occurrence of higher temperatures in urban areas than the neighbouring rural areas. The neighbouring land cover also has some influence on the urban temperatures. The present study focuses on the UHI effect observed in four different cities i.e. Bikaner, Hyderabad, Vadodara and Varanasi which were surrounded by different natural land covers using MODIS satellite images. Bikaner shows Urban Cool Island (UCI) and Varanasi show UHI during day time. Vadodara and Hyderabad do not show much variation in urban and rural LST during day time. However, UHI effect was found clearly significant during night time in the four cities. UHI intensity was calculated using night LST and found highest in Hyderabad and lowest in Bikaner. The relation of LST with \% Impervious was studied which shows good positive linear relation when significant UHI effect was observed and negative linear relation when UCI effect was observed. The slope obtained from linear regression of night LST with \% Impervious was compared with the UHI intensity in the four cities and found to show good positive linear relation. Therefore, \% Impervious can be used to quantify UHI intensity in urban areas.
\end{abstract}

\section{INTRODUCTION}

The occurrence of higher temperatures in urban areas than the neighbouring rural areas is commonly referred to as urban heat island (UHI). The major cause for UHI effect is the rapid increase in urbanization which has replaced large amount of natural land surfaces with artificial built surfaces made up of non-evaporating impervious materials which absorbs radiation during the day and re-radiates during the night time (Voogt and Oke, 2003), increase in anthropogenic heat discharge by industries, vehicles, and buildings, and also the decrease in vegetation that has the ability to reduce the temperatures through evapotranspiration. Higher temperature in urban areas increases the demand for air conditioners, raises the pollution levels, increases dryness and also modifies the natural cycle of precipitation (Kato and Yamaguchi, 2005). As a result, study of Land Surface Temperature (LST) of urban areas has become important for the requirement of sustainable planning and environmental protection (Kauffman et al. 2007; Nuruzzaman, 2015).

Thermal bands from the satellite data like MODIS, Landsat and are widely used for determination of LST at different spatial and temporal resolution. UHI formation depends on various factors like the type of natural land cover surrounding the urban area or the time of the study (Chen et al. 2006, Bala et al. 2018). Various studies have been performed to study the relation of LST with different independent variables like Normalized

Difference Vegetation Index (NDVI), Normalized Difference Built-up Index (NDBI), percent impervious surfaces ( $\mathrm{Li}$ et al. 2018, Bala et al. 2019, Yuan and Bauer, 2007). Moderate Resolution Imaging Spectro-radiometer
(MODIS) data provides LST images for day as well as night time. The behaviour of LST of different land covers varies for day and night time (Rasul et al. 2016). So, the present study focuses on the determination of UHI effect in different cities i.e. Bikaner, Hyderabad, Vadodara and Varanasi surrounded by different natural land covers during day and night time using MODIS satellite data. The relation of MODIS LST with percent impervious obtained from Landsat 8 data was also studied for both day and night time and compared with UHI intensity in the four urban regions in the study.

\section{STUDY AREA AND DATA USED}

\subsection{Study Area}

The study areas were chosen based on the surrounding natural land covers in the cities. Four different cities of India were selected for the study i.e. Hyderabad, Bikaner, Vadodara and Varanasi as shown in Figure (1). The maps of the four cities are the false colour composite images obtained from Landsat data.

Hyderabad is located in south east part of India with coordinates $17.37{ }^{0} \mathrm{~N}, 78.48{ }^{0} \mathrm{E}$ covers an area of $650 \mathrm{~km}^{2}$ and at an average elevation of $542 \mathrm{~m}$. The city lies on small hills of pink and grey granite and consists of numerous lakes. Vadodara is located at $22.30^{\circ} \mathrm{N}, 73.19^{\circ} \mathrm{E}$ in western India at an elevation of $39 \mathrm{~m}$ with an area of $235 \mathrm{~km}^{2}$. The city is located on the fertile plain between the Mahi and Narmada Rivers. Bikaner is located in the north western part of India with coordinates $28.01{ }^{0} \mathrm{~N}, 73.31{ }^{0} \mathrm{E}$ covers an area of 155 $\mathrm{km}^{2}$ and at an average elevation of $242 \mathrm{~m}$ and is situated in 
the middle of the Thar desert. Varanasi is located in the northern part of India with coordinates $25.28{ }^{0} \mathrm{~N}, 82.96{ }^{0} \mathrm{E}$ covers an area of $82.1 \mathrm{~km}^{2}$ and at an average elevation of $80.71 \mathrm{~m}$ and is situated at the bank of river Ganges. Different cities consist of different surrounding natural land covers.

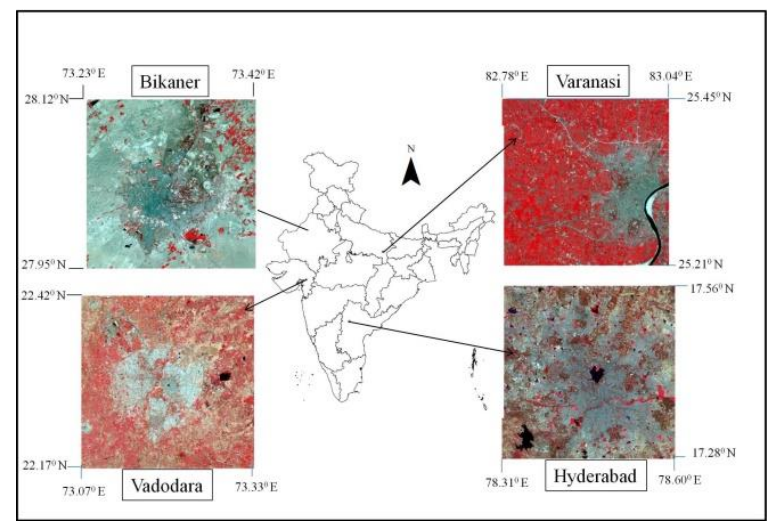

Figure 1. Location map of study area

\subsection{Data Used}

LST (MOD11A2) of MODIS sensor aboard Terra satellite was downloaded for the four cities from the USGS LPDAAC (Land Processes Distributed Active Archive Center) website i.e. https://pdaac.usgs.gov/. MOD11A2 products provide 8-day composite LST images with $930 \mathrm{~m}$ spatial resolution. All the MODIS images were reprojected and resampled using Modis Reprojection Tool (MRT). Landsat 8 Operational Land Imager (OLI) data of Landsat Level 1 Data products were also downloaded from the US Geological Survey website i.e. https://earthexplorer.usgs.gov/ for the four study sites. Landsat 8 images have $30 \mathrm{~m}$ spatial resolution, 16-day temporal resolution and 12-bit radiometric resolution. All the images were obtained in clear sky conditions. Details of the satellite data acquired are shown in Table (1).

\begin{tabular}{|c|c|c|c|c|}
\hline \multirow[t]{2}{*}{ Cities } & \multicolumn{2}{|c|}{$\begin{array}{l}\text { Landsat } 8 \text { OLI } \\
\text { data }\end{array}$} & \multicolumn{2}{|l|}{$\begin{array}{l}\text { MODIS data } \\
\text { (MOD11A2) }\end{array}$} \\
\hline & Date & $\begin{array}{l}\text { Path/R } \\
\text { ow }\end{array}$ & $\begin{array}{l}\text { Composite } \\
\text { Dates }\end{array}$ & Tiles \\
\hline Bikaner & $22 / 02 / 2017$ & $149 / 41$ & $\begin{array}{ll}18 / 02 / 2017 & - \\
25 / 02 / 2017 & \\
\end{array}$ & $\begin{array}{l}\mathrm{h} 24 \mathrm{v} 0 \\
6\end{array}$ \\
\hline $\begin{array}{l}\text { Hyderaba } \\
\text { d }\end{array}$ & $19 / 02 / 2017$ & $144 / 48$ & $\begin{array}{l}18 / 02 / 2017 \\
25 / 02 / 2017\end{array}$ & $\begin{array}{l}\mathrm{h} 25 \mathrm{v} 0 \\
7\end{array}$ \\
\hline Vadodara & $03 / 03 / 2017$ & $148 / 45$ & $\begin{array}{l}26 / 02 / 2017 \\
05 / 03 / 2017 \\
\end{array}$ & $\begin{array}{l}\mathrm{h} 24 \mathrm{v} 0 \\
6 \\
\end{array}$ \\
\hline Varanasi & $21 / 02 / 2017$ & $142 / 42$ & $\begin{array}{l}18 / 02 / 2017 \\
25 / 02 / 2017 \\
\end{array}$ & $\begin{array}{l}\mathrm{h} 25 \mathrm{v} 0 \\
6 \\
\end{array}$ \\
\hline
\end{tabular}

Table 1. Details of satellite data

\section{METHODOLOGY}

\subsection{Percent impervious classification}

A normalized spectral mixture analysis (NSMA) approach was used for the classification of percent impervious surface from the mixed spectrum which was modeled as a linear combination of vegetation-impervious-soil (V-I-S) endmembers ( $\mathrm{Wu}, 2004)$. First, the reflectance bands of original Landsat 8 data were normalized.

$$
\bar{R}_{b}=\frac{R_{b}}{m} \times 100
$$

Where, $\quad m=\frac{1}{n} \sum_{b=1}^{n} R_{b}=$ the average reflectance in a pixel,

$\overline{R_{b}}=$ the normalized reflectance for band $\mathrm{b}$,

$R_{b}=$ the original reflectance of band $\mathrm{b}$ and

$\mathrm{n}=$ the total number of bands.

Further, Linear spectral mixture analysis (LSMA) approach was used for calculation of fractions of the four endmembers contained in a pixel. The linear mixture model is represented as

$$
\overline{R_{b}}=\sum_{i=1}^{n^{\prime}} \bar{f}_{i} \bar{R}_{i, b}+e_{b}
$$

Where, $\sum_{i=1}^{n} \bar{f}_{i}=1$ and $\bar{f}_{i} \geq 0$;

$\bar{f}_{i}=$ the fraction of endmember $i$,

$\bar{R}_{i, b}=$ the normalized reflectance of endmember $i$ in band $b$,

$n^{\prime}=$ the number of endmembers and

$e_{b}=$ the residual.

The fraction is determined using a least squares method by minimizing the residual $e_{b .}$. The percent impervious image was obtained for the four cities at $30 \mathrm{~m}$ spatial resolution which was aggregated to that of MODIS spatial resolution $(930 \mathrm{~m})$ for the present study.

\subsection{Determination of UHI intensity}

Modis LST images were obtained from by rescaling MODIS LST product by a factor of 0.02 which provides LST images in degree Kelvin. So, further the image was subtracted by a factor of 273.15 which provides LST images in degree Celsius. In order to study UHI intensity in four different cities, a normalization method was performed using the following Equation (3) (Abutaleb et al. 2015).

$$
U H I=\frac{T_{s}-T_{m}}{S D}
$$

where, $\mathrm{T}_{\mathrm{s}}=$ the LST of a pixel,

$\mathrm{T}_{\mathrm{m}}$ is the mean LST of an image and

SD is the standard deviation of an LST image.

This UHI image was further classified into 3 categories as shown in Table 2 (Ahmed, 2018).

\begin{tabular}{|c|c|}
\hline UHI $<-0.5$ & Rural \\
\hline$-0.5 \leq \mathrm{UHI} \leq 0.5$ & Sub-urban \\
\hline $\mathrm{UHI}>0.5$ & Urban \\
\hline
\end{tabular}

Table 2. Classification from UHI image

Using zonal statistics, mean LST for rural and urban areas were determined and then UHI intensity was calculated using Equation (4) (Keeratikasikorn and Bonafoni, 2017).

$$
\Delta \mathrm{T}=\mathrm{T}_{\text {urban }}-\mathrm{T}_{\text {rural }}
$$

where, $\mathrm{T}_{\text {urban }}=$ the mean urban LST and

$\mathrm{T}_{\text {rural }}=$ the mean rural LST.

The value of $\Delta \mathrm{T}$ determines the UHI intensity. 


\section{RESULT AND DISCUSSIONS}

Modis day and night LST images of the four cities are shown in figure 2.

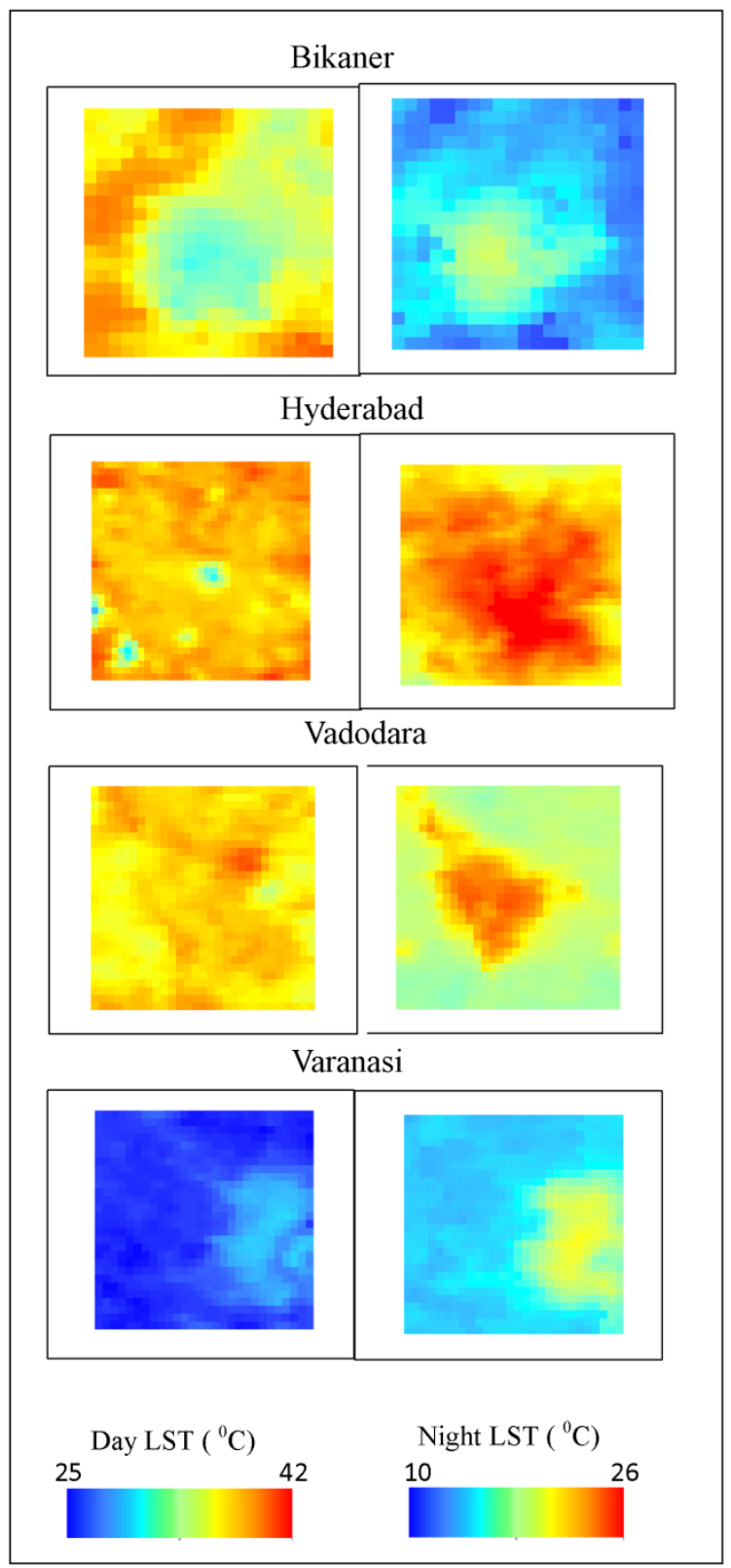

Figure 2. Day and night Modis LST maps of the study sites

The urban part of Bikaner shows lower LST during day time than the surrounding rural areas resulting in urban cool Island (UCI) but significant UHI effect was observed during night time. Since, Bikaner is surrounded by desert, the sand or bare soil has very low heat capacity which absorbs heat fast during day time and also releases heat fast during night time (Rasul et al. 2016). Therefore, this results in UCI effect during day time and UHI effect during night time. In Hyderabad, significant UHI effect was observed during night time but not during day time. The city is surrounded by small hills made up of rocks which show higher temperature during day time but lower LST during night time. Vadodara shows good UHI effect during night time but not during day time because the city is surrounded by agricultural areas that was sparsely vegetated in some regions and some bare lands. The vegetated areas show LST slightly lower but bare land shows higher LST than the urban areas resulting in absence of UHI effect during day time. Varanasi city was surrounded by vegetation which results in UHI effect during both day and night time because vegetation has low LST values for day as well as night time. Therefore, it was observed that UHI effect was found significant during night time in the four cities independent of the surrounding natural land covers (Shastri et al. 2017).

\begin{tabular}{|c|c|c|c|c|}
\hline \multirow{2}{*}{ City } & \multicolumn{2}{|c|}{ Day LST $\left({ }^{0} \mathrm{C}\right)$} & \multicolumn{2}{c|}{ Night LST $\left({ }^{\circ} \mathrm{C}\right)$} \\
\cline { 2 - 5 } & Min & Max & Min & Max \\
\hline Bikaner & 31 & 41 & 9 & 19 \\
\hline Hyderabad & 28 & 43 & 18 & 27 \\
\hline Vadodara & 34 & 41 & 17 & 25 \\
\hline Varanasi & 25 & 30 & 14 & 20 \\
\hline
\end{tabular}

Table 3. Specification of day and night LST in the cities

From Table 3, it was observed that different cities show different LST behaviour during day and night time. Bikaner shows very high LST during day time but very low during night time. Varanasi show lower LST during day time than other cities and the decrease in LST during night was found very low. Vadodara also shows high LST during day time but the decrease in LST during night time was less than that in Bikaner but higher than that in Varanasi. This was due to the presence of both sparse vegetation and bare soil in the rural areas. In Hyderabad, max LST was due to the rocks on the hills and min LST due to the waterbody in urban areas during day time but during night time urban areas shows higher LST and surrounding region show lower LST. Therefore, LST in urban areas do not show much variation from day to night time. Hence, the heat absorbed by the urban areas during day time gets trapped due to less convection in Hyderabad. Therefore, the surrounding land covers was found to influence the LST value in urban areas.

Figure 3 shows the spatial variation in LST from day to night time in the four study sites. During day time, all the land covers acquire heat from the sun and raises the temperature whereas during night time, temperature of all land cover starts decreasing due to the absence of heat energy. This increase or decrease in LST of land covers depends on the heat capacity of the material.

Heat capacity is the amount of heat or energy required to change the temperature of the system by $1 \mathrm{~K}$. It was observed that the urban areas and waterbodies show lower variation in LST. This was due to the higher heat capacity of water $\left(4.2 \mathrm{~kJ} \mathrm{~kg}^{-1} \mathrm{~K}^{-1}\right)$ and the urban built up materials $((0.9$ - 1.7) $\mathrm{kJ} \mathrm{kg}^{-1} \mathrm{~K}^{-1}$ ). The desert in Bikaner shows the greatest variation due to the low heat capacity of bare soil/sand $(0.8$ $\mathrm{kJ} \mathrm{kg}^{-1} \mathrm{~K}^{-1}$ ). The vegetation in Varanasi shows comparatively lower variation due to the evapotranspiration process. Therefore, UHI effect was significant during night time due to its capability to hold the heat energy for longer duration. 


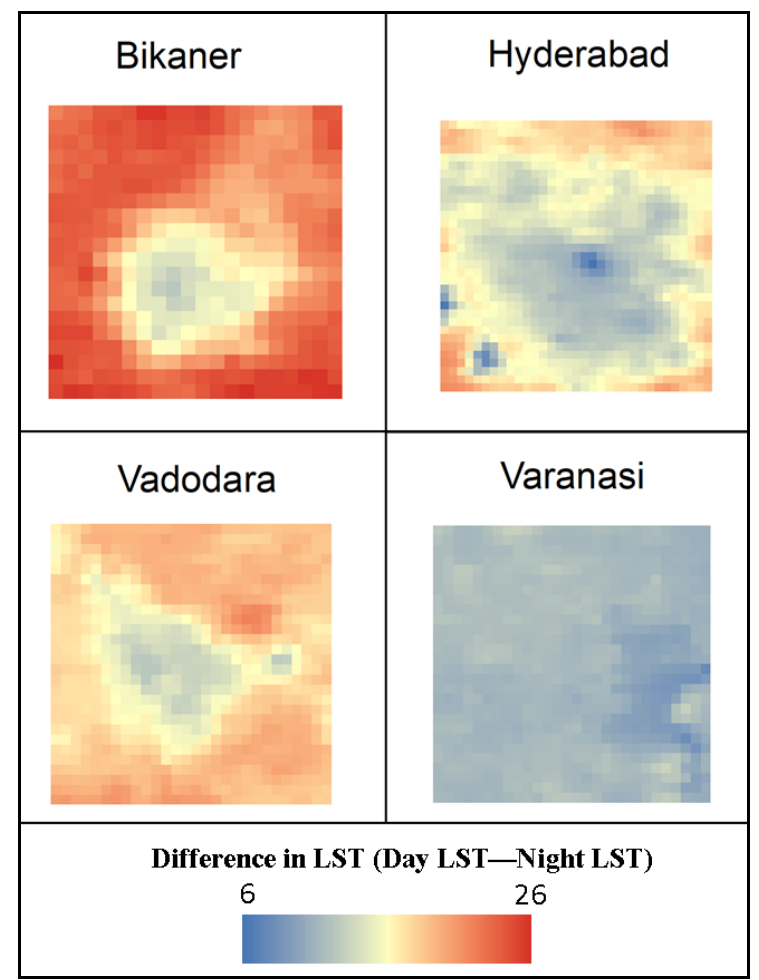

Figure 3. Spatial heat difference of day and night LST for Bikaner, Hyderabad, Vadodara and Varanasi.

Figure 4 shows the relation of LST with \% Impervious varies for four different cities. Bikaner shows negative relation for day time and positive linear relation for night time. Hyderabad and Vadodara do not show good relation for day time whereas good positive linear relation was obtained for night time. Varanasi shows good positive linear relation for both day and night time. Therefore, good positive linear relation was observed for the four cities during night time whereas the relation was found to vary for different cities during day time. Further, we can conclude that good positive linear relation was observed when significant UHI effect was observed and negative linear relation was observed when UCI effect was observed. Hence, percent impervious can be considered as the indicator of UHI effect (Yuan and Bauer, 2007).

Table 4 shows the slope, intercept and coefficient of determination $\left(\mathrm{R}^{2}\right)$ for the linear regression of the relation of night LST with \% Impervious. The slope was found to vary for different cities. The $\mathrm{R}^{2}$ reveals the good positive relation of night LST with \% Impervious surfaces. The slope can be used to quantify UHI effect ( $\mathrm{Li}$ et al. 2018). Night LST was used for further study to compare the UHI intensity in the four cities. UHI intensity was plotted with the slope of linear relation of night LST with \% Impervious as shown in figure 5. It was observed that the UHI intensity shows positive linear relation with the slope of night LST with \% Impervious.

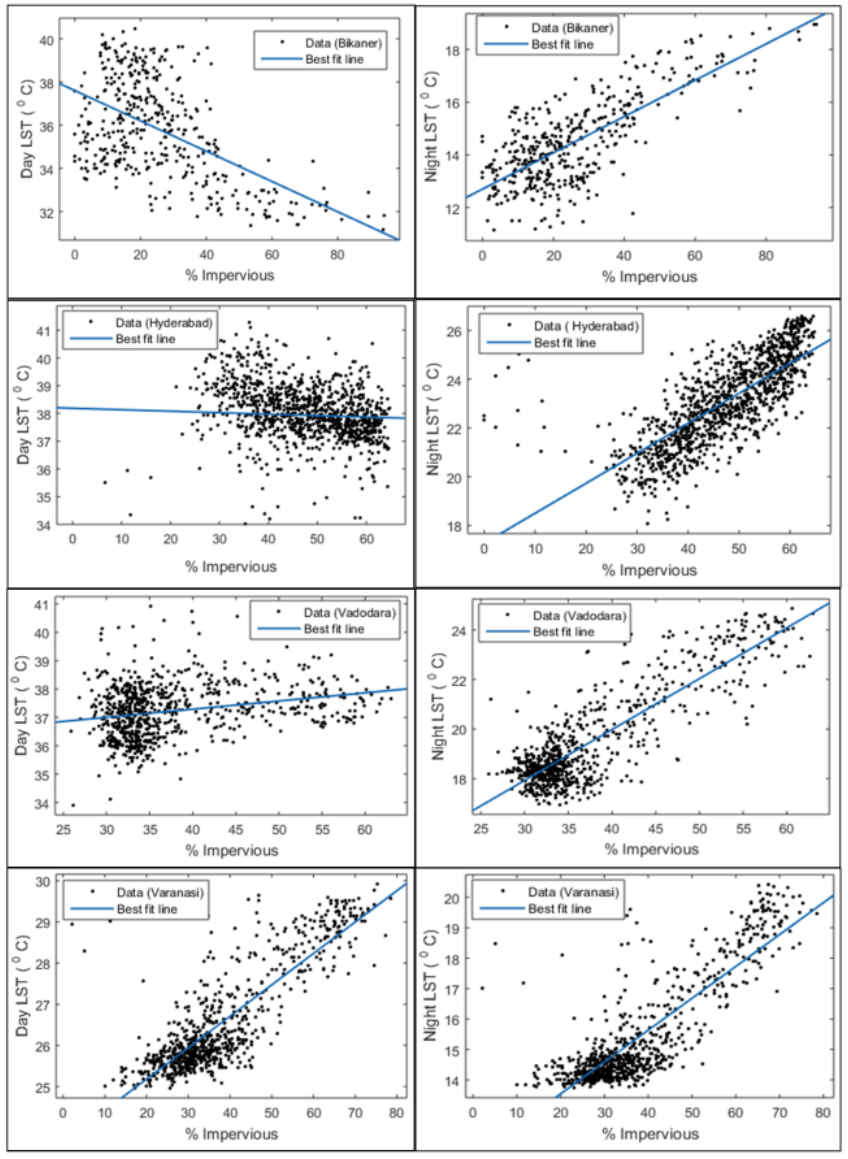

Figure 4. Scatterplot of day and night LST with \% Impervious for Bikaner, Hyderabad, Vadodara and Varanasi.

\begin{tabular}{|c|c|c|}
\hline \multirow{2}{*}{ City } & \multicolumn{2}{|c|}{ Linear regression } \\
\cline { 2 - 3 } & Equation & $\mathrm{R}^{2}$ \\
\hline Bikaner & $\mathrm{y}=0.07 \times \mathrm{x}+12.7$ & 0.65 \\
\hline Hyderabad & $\mathrm{y}=0.19 \times \mathrm{x}+17.3$ & 0.66 \\
\hline Vadodara & $\mathrm{y}=0.12 \times \mathrm{x}+11.8$ & 0.75 \\
\hline Varanasi & $\mathrm{y}=0.10 \times \mathrm{x}+11.5$ & 0.73 \\
\hline
\end{tabular}

Table 4. The equation and coefficient of determination $\left(\mathrm{R}^{2}\right)$ for the linear regression for night LST with \% Impervious.

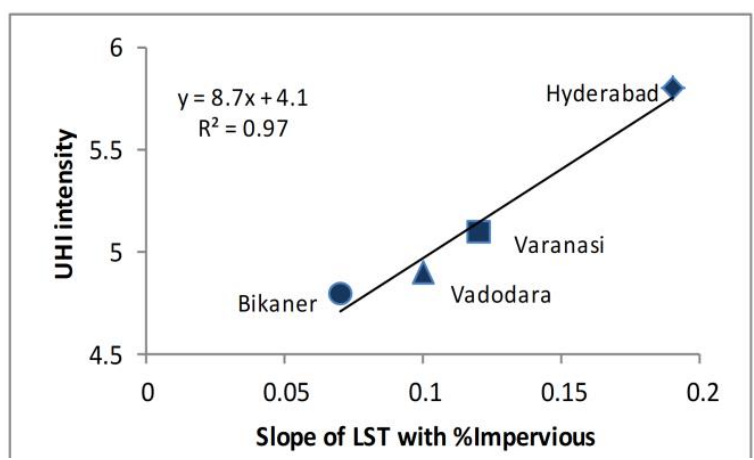

Figure 5. Plot of UHI intensity with the slope of linear relation of night LST with \% Impervious

UHI intensity was found higher in Hyderabad because the surrounded hills reduces wind velocity and heat gets trapped 
due to less convection resulting in higher UHI intensity during night time. The urban region shows different UHI intensity due to the land cover surrounding the cities. Bikaner shows lower temperature difference in urban and rural land covers whereas Varanasi shows comparatively higher temperature difference.

\section{CONCLUSIONS}

The variation of UHI Intensity in urban cities of Bikaner, Hyderabad, Vadodara and Varanasi were studied using MODIS satellite data. The Modis LST images were obtained for day as well as night time. Bikaner shows UCI and Varanasi show UHI during day time. Vadodara and Hyderabad do not show much variation in urban and rural LST during day time. However, UHI effect was found significant during night time in the four study sites independent of the surrounding land cover. The natural land cover around the cities was found to show significant impact on urban temperatures.

Further, relation of LST with \% Impervious was studied which shows good positive linear relation when significant UHI effect was observed and negative linear relation when UCI effect was observed. The slope obtained from linear regression of night LST with \% Impervious was compared with the UHI intensity in the four cities and found to show good positive linear relation. UHI intensity was found highest in Hyderabad which was surrounded by small hills due to less convection and lowest in Bikaner which was surrounded by desert. Therefore, \% Impervious can be used to quantify UHI intensity in urban areas.

\section{ACKNOWLEDGEMENT}

The authors are thankful to the Council of Scientific and Industrial Research (CSIR), New Delhi for providing financial support and also NASA for providing free access to the satellite data used in the present study.

\section{REFERENCES}

Abutaleb, K., Ngie, A., Darwish, A., Ahmed, M., Arafat, S., Ahmed, F. (2015). Assessment of Urban Heat Island using remote sensed imagery over greater Cairo, Egypt. Adv. Remote Sens. 4, 3547 .

Ahmed, S. (2018). Assessment of urban heat islands and impact of climate change on socioeconomic over Suez Governorate using remote sensing and GIS techniques. The Egyptian Journal of Remote Sensing and Space Sciences. 21, 15-25.
Bala, R., Prasad, R., Yadav, V. P. (2019). Disaggregation of modis land surface temperature in urban areas using improved thermal sharpening techniques, Advances in Space Research, ISSN: 02731177, https://doi.org/10.1016/j.asr.2019.05.004.

Bala, R., Prasad, R., Yadav, V.P., Sharma, J. (2018). A Comparative Study of Land Surface Temperature with Different Indices on Heterogeneous Land Cover using Landsat 8 Data. Int. Arch. Photogramm. Remote Sens. Spatial Inf. Sci. XLII-5, 389-394.

Chen, X. L., Zhao, H.M., Li, P. X., Yin, Z. Y. (2006). Remote sensing image-based analysis of the relationship between urban heat island and land use/ cover changes. Remote Sensing of Environment, vol. 104 (2), 133-146.

Kato, S., Yamaguchi. Y. (2005). Analysis of urban heat-island effect using ASTER and ETM+ Data: Seperation of anthropogenic heat discharge and natural heat radiation from sensible heat flux. Remote Sens. Environ. 99, 44-54.

Kauffman, R. K., K. C. Seto, A. Schneider, Z. Liu, L. Zhou, and W. Wang. (2007). Climate response to rapid urban growth: evidence of a human-induced precipitation deficit. Journal of Climate. 20, 22992306.

Keeratikasikorn, C., Bonafoni, S. (2018). Urban Heat Island Analysis over the Land Use Zoning Plan of Bangkok by Means of Landsat 8 Imagery. Remote Sens. 10, 440.

Li, H., Zhou, Y., Li, X., Meng, L., Wang, X., Wu, S., Sodoudi, S. (2018). A new method to quantify surface urban heat island intensity. Science of the Total Environment. 624, 262-272.

Md. Nuruzzaman., (2015). Urban Heat Island: Causes, Effects and Mitigation Measures - A Review. International Journal of Environmental Monitoring and Analysis.3 (2), pp. 67-73.

Rasul, A., Balzter, H., Smith, C. (2016). Diurnal and Seasonal Variation of Surface Urban Cool and Heat Islands in the Semi-Arid City of Erbil, Iraq. Climate. 4, 42.

Shastri, H., Barik, B., Ghosh, S., Venkataraman, C., Sadavarte, P. (2017). Flip flop of Day-night and Summer-Winter Surface Urban Heat Island Intensity in India. Scientific Reports, 7, 40178.

Voogt, J. A., Oke, T. R. (2003). Thermal remote sensing of urban areas. Remote sensing of Environment, vol. 86, pp. 370-384.

Wu, C. (2004). Normalized Spectral Mixture Analysis for Monitoring Urban Composition Using ETM+ Imagery. Remote Sensing of Environment. 93 (4), 480-492.

Yuan, F., Bauer, M.E. (2007). Comparison of impervious surface area and normalized difference vegetation index as indicators of surface urban heat island effects in Landsat imagery. Remote Sensing of Environment. 106, 375-386

Revised August 2019 